\title{
Wall stresses of early remodeled pulmonary autografts
}

Yue Xuan, $\mathrm{PhD},{ }^{\mathrm{a}}$ Edgardo Alonso, BS, ${ }^{\mathrm{a}}$ Alexander Emmott, $\mathrm{PhD},{ }^{\mathrm{b}}$ Zhongjie Wang, PhD,

Shalni Kumar, BS, ${ }^{\mathrm{a}}$ Francois-Pierre Mongeon, MD, ${ }^{\mathrm{c}}$ Richard L. Leask, PhD, ${ }^{\mathrm{b}}$ Ismail El-Hamamsy, MD, ${ }^{\mathrm{d}}$

Liang $\mathrm{Ge}, \mathrm{PhD},{ }^{\mathrm{a}}$ and Elaine E. Tseng, $\mathrm{MD}^{\mathrm{a}}$

\section{ABSTRACT}

Objective: The Ross procedure is an excellent option for children or young adults who need aortic valve replacement because it can restore survival to that of the normal aged-matched population. However, autograft remodeling can lead to aneurysmal formation and reoperation, and the biomechanics of this process is unknown. This study investigated postoperative autograft remodeling after the Ross procedure by examining patient-specific autograft wall stresses.

Methods: Patients who have undergone the Ross procedure who had intraoperative pulmonary root and aortic specimens collected were recruited. Patient-specific models $(n=16)$ were developed using patient-specific material property and their corresponding geometry from cine magnetic resonance imaging at 1-year followup. Autograft \pm Dacron for aneurysm repair and ascending aortic geometries were reconstructed to develop patient-specific finite element models, which incorporated material properties and wall thickness experimentally measured from biaxial stretching. A multiplicative approach was used to account for prestress geometry from in vivo magnetic resonance imaging. Pressure loading to systemic pressure (120/80) was performed using LS-DYNA software (LSTC Inc, Livermore, Calif).

Results: At systole, first principal stresses were $809 \mathrm{kPa}(25 \%-75 \%$ interquartile range, 691-1219 $\mathrm{kPa}), 567 \mathrm{kPa}(485-675 \mathrm{kPa}), 637 \mathrm{kPa}(555-755 \mathrm{kPa})$, and $382 \mathrm{kPa}$ $(334-413 \mathrm{kPa})$ at the autograft sinotubular junction, sinuses, annulus, and ascending aorta, respectively. Second principal stresses were $360 \mathrm{kPa}(310-426 \mathrm{kPa}), 355 \mathrm{kPa}$ (320-394 kPa), $272 \mathrm{kPa}(252-319 \mathrm{kPa})$, and $184 \mathrm{kPa}(147-222 \mathrm{kPa})$ at the autograft sinotubular junction, sinuses, annulus, and ascending aorta, respectively. Mean autograft diameters were $29.9 \pm 2.7 \mathrm{~mm}, 38.3 \pm 5.3 \mathrm{~mm}$, and $26.6 \pm 4.0 \mathrm{~mm}$ at the sinotubular junction, sinuses, and annulus, respectively.

Conclusions: Peak first principal stresses were mainly located at the sinotubular junction, particularly when Dacron reinforcement was used. Patient-specific simulations lay the foundation for predicting autograft dilatation in the future after understanding biomechanical behavior during long-term follow-up. (J Thorac Cardiovasc Surg 2022;164:1728-38)

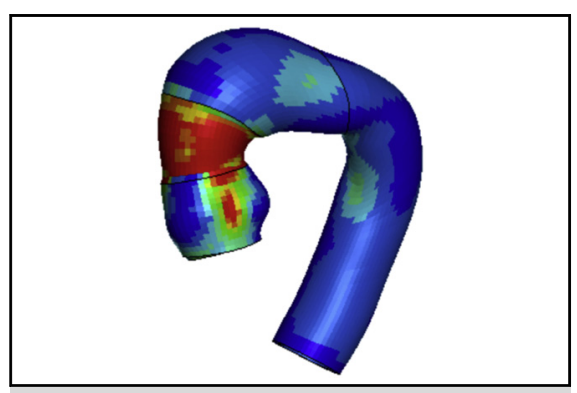

First principal stresses of representative patientspecific autograft, ascending aorta, and Dacron graft.

\section{CENTRAL MESSAGE}

At 1 year postoperatively, patientspecific simulations after the Ross procedure revealed that all autograft regions had elevated wall stresses compared with native distal aorta without early dilatation.

\section{PERSPECTIVE}

Elevated wall stresses may lead to autograft dilatation requiring reoperation. Using FE modeling of patient-specific autografts, we found wall stresses in all autograft regions were greater than in the distal ascending aorta without concurrent dilatation at 1 year after the Ross operation. Our work provides the necessary first step toward understanding how autograft wall stresses lead to dilatation.

See Commentaries on pages 1739 and 1740.
From the a Division of Cardiothoracic Surgery, Department of Surgery, University of California San Francisco Medical Center and San Francisco VA Medical Center, San Francisco, Calif; ' Department of Chemical Engineering, McGill University, Montreal, Quebec, Canada; ${ }^{\mathrm{C}}$ Division of Cardiology, Department of Medicine, Montreal Heart Institute, Montreal, Quebec, Canada; and ${ }^{\mathrm{d}}$ Department of Cardiovascular Surgery, Icahn School of Medicine at Mount Sinai, New York, NY.

This study was funded by American Heart Association Postdoctoral Fellowship 16POST31420013 (Y.X.), UCSF PROF-PATH/Summer Excellence Research Fellowship (E.A.), and National Institutes of Health R01HL119857-01A1 (E.E.T. and L.G.).

CHR Approval Number: 15-16989, 12-08529, 2021-2927. Institutional Review Board waived the need for written informed patient consent for publication.

Y.X. and E.A. contributed equally to the current work.
Presented at the American College of Surgeons Clinical Congress 2020 Scientific Forum, Exclusive Virtual Event, October 4-7, 2020.

Received for publication Aug 3, 2020; revisions received Aug 12, 2021; accepted for publication Aug 23, 2021; available ahead of print Aug 31, 2021.

Address for reprints: Elaine E. Tseng, MD, Division of Cardiothoracic Surgery, University of California San Francisco, San Francisco VA Medical Center, 500 Parnassus Ave, Suite 405W, San Francisco, CA 94143 (E-mail: Elaine.Tseng@ucsf.edu). 0022-5223

Published by Elsevier Inc. on behalf of The American Association for Thoracic Surgery. This is an open access article under the CC BY-NC-ND license (http:// creativecommons.org/licenses/by-nc-nd/4.0/). https://doi.org/10.1016/j.jtcvs.2021.08.058 

Abbreviations and Acronyms
$\mathrm{FE}=$ finite element
FEA $=$ finite element analysis
$\mathrm{MAP}=$ mean arterial pressure
MRI $=$ magnetic resonance imaging
STJ $=$ sinotubular junction

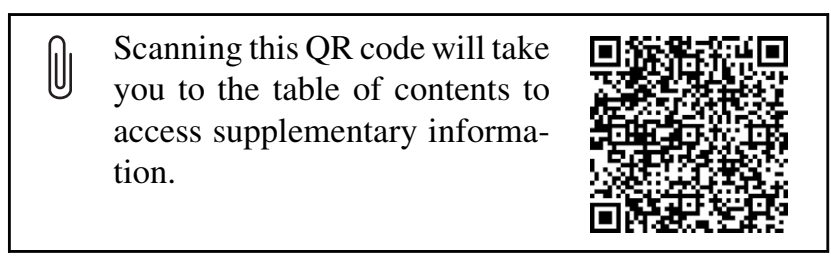

The Ross procedure has emerged as an ideal choice for surgical aortic valve replacement in pediatric patients and young adults ${ }^{1,2}$ who want an active lifestyle and prefer to avoid lifelong anticoagulation. Benefits of the Ross procedure also include excellent hemodynamics and a living valve that can grow with children and young adults. More important, recent evidence suggests that the pulmonary autograft restores a patient's life span to the normal age-matched population-based survival. ${ }^{3-5}$ Controversies regarding the Ross procedure remain: converting a single to double valve operation; increased technical complexity compared with mechanical or stented bioprosthetic valve replacement; need for reoperation due to autograft dilatation with aneurysm formation or aortic insufficiency; and need for reoperation for pulmonary homograft stenosis. ${ }^{6,7}$ Specialized centers ${ }^{5,8-11}$ with Ross expertise have largely overcome issues with the technical complexity of the operation, demonstrating excellent operative outcomes, whereas oversized pulmonary homografts have decreased concerns regarding homograft stenosis. ${ }^{12}$

Pulmonary autograft dilatation remains the primary concern and can lead to reoperation due to aneurysm formation or autograft valve insufficiency, although reported reoperation rates vary among different institutions. ${ }^{2,13,14}$ Ross techniques vary, including subcoronary, ${ }^{15,16}$ full root with and without native aortic support, ${ }^{11,17,18}$ root inclusion, ${ }^{11}$ differences in length of pulmonary artery used, and use of autograft annulus or sinotubular junction (STJ) reinforcement. ${ }^{19,20}$ Such technical differences have been cited as potential causes for differences in long-term reoperation rates ${ }^{17}$ for the full root replacement technique. Fundamentally, the autograft root is transposed from the lowpressure pulmonary environment to the high-pressure systemic one. Normally, the pulmonary root experiences a mean arterial pressure (MAP) of approximately $15 \mathrm{~mm} \mathrm{Hg}$ in adult pulmonary circulation, whereas MAP in systemic circulation is approximately $93 \mathrm{~mm} \mathrm{Hg}$, a greater than 6 times pressure change for the autograft immediately after transposition. Previously, we demonstrated in a single human autograft finite element (FE) model that wall stresses on the autograft root increased dramatically upon immediate exposure to systemic pressure without concurrent dilatation. ${ }^{21}$ These wall stress changes may trigger and influence autograft remodeling including increased wall thickness and compliance, changes we have shown evident in late failed aneurysmal autografts 13 years after initial Ross operation. ${ }^{22}$ However, not all autografts dilate; therefore, determining the degree of increased autograft wall stresses after the Ross procedure may aid understanding of the risk of longterm dilatation and aneurysm formation. Yet, the nature of postoperative autograft biomechanics in any given patient is unknown. Our objective in this hypothesis-generating study was to examine patient-specific autograft wall stresses after the Ross procedure using patient-specific imaging at 1 year postoperatively combined with corresponding material properties determined from intraoperative tissue specimens to initiate our longitudinal tracking in correlation with early remodeling. To our knowledge, this is the first work that presents patient-specific stress distribution using image-based geometry and experimentally measured material properties for each patient combined with the detailed surgery technique with and without Dacron replacement of the dilated ascending aorta. Because wall stress cannot be directly measured in vivo, we performed finite element analysis (FEA) using patient-specific geometry and material properties to determine autograft wall stresses.

\section{MATERIALS AND METHODS}

Patients undergoing the Ross procedure were recruited consecutively at the Montreal Heart Institute $(\mathrm{n}=290)$ and the subset of patients with both follow-up 1-year magnetic resonance imaging (MRI) and intraoperative pulmonary root specimen collection for patient-specific material properties were included in the study $(\mathrm{n}=16)$. The study was approved by the Institutional Review Board at Montreal Heart Institute, San Francisco Veterans Affairs Medical Center, and Committee on Human Research at University of California San Francisco; written informed consent was waived for publication. Pulmonary root samples for all patients $(\mathrm{n}=16)$ and ascending aortic samples for most patients $(n=10)$ were excised intraoperatively via a standardized approach, performed by a single surgeon. Specimens for biaxial stretch testing were taken from the anterior quadrant $3 \mathrm{~mm}$ distally above the respective commissures for pulmonary and aortic roots. Patients at the time of operation with enlarged ascending aortic diameters additionally underwent an interposition Dacron graft. ${ }^{17}$ Extracted specimens underwent biaxial stretch testing up to $75 \%$ strain as previously described $^{23}$ to measure patient-specific material properties. The stressstrain data were then fitted to the fiber-embedded hyperelastic material model $^{24}$ to derive the patient-specific material property parameters (Table E1). Sample thicknesses were measured. Deidentified MRI scans were transferred to the San Francisco Veterans Affairs Medical Center for patient-specific FE modeling.

\section{Development of Patient-Specific Models}

Patient-specific simulations integrated image-based geometry and experimental measurements of material properties for each patient. Also, a fiber-embedded hyperelastic material model was used to represent the 
nonlinear material property of aortic and pulmonary tissues. The material model has been described, ${ }^{24}$ and the governing equation of the 2 groups of dispersed collagen fibers is listed:

$$
\Psi_{\text {collageni }}(\mathbf{C})=\frac{k_{1}}{2 k_{2}}\left[\exp \left(k_{2} \bar{E}_{i}^{2}\right)-1\right], i=1,2
$$

where $\bar{E}_{i}$ is an invariant that reflects the impact of each fiber family deformation on strain energy function, and $k_{1}$ and $k_{2}$ are material parameters determined by mechanical testing of the material. The patient-specific material properties were also averaged and used in a second set of pressure simulations for each patient model to compare the impact of patientspecific material properties versus the group averaged material properties on wall stress (Table E1).

MRI scans acquired 1 year postoperatively were then manually contoured under diastolic pressure to reconstruct 3-dimensional geometry of pulmonary autograft and distal ascending aorta. Images were exported as Digital Imaging and Communications in Medicine files and imported into MeVisLab (http://www.mevislab.de/home/about-mevislab) for image segmentation. Next, smooth 3-dimensional surfaces with patient-specific thicknesses (Figure 1) were constructed and imported into TrueGrid (XYZ Scientific, Applications, Inc, Pleasant Hills, Calif) to generate FE hexahedral meshes (Figure 1) that were subsequently imported into LS-
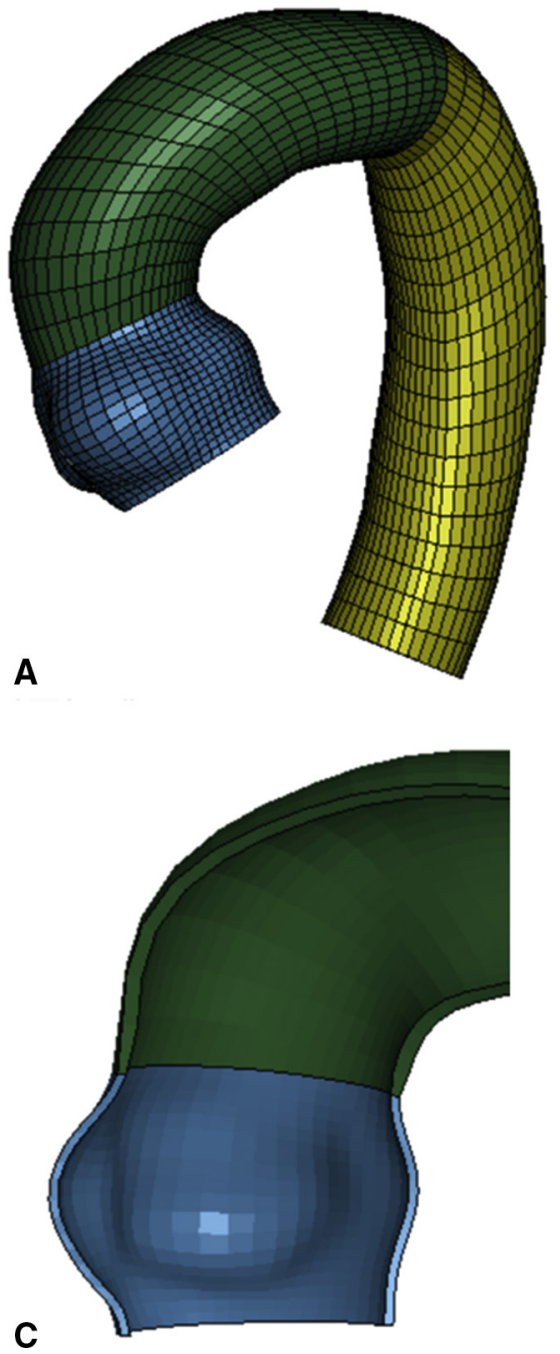

DYNA (LSTC Inc, Livermore, Calif) for physiologic pressure simulations Because in vivo images represented prestressed geometries under in vivo physiologic blood pressures, we used a modified-update Lagrangian method to account for prestress through an iterative process. ${ }^{24}$ Distal ascending aorta and pulmonary autograft were modeled as incompressible hyperelastic material, composed of extracellular matrix reinforced with dispersed collagen fibers. ${ }^{24}$ As previously described, dynamic simulations were performed by applying physiologic systemic pressure loading conditions to inner lumens. ${ }^{21}$ Physiologic cardiac cycle of $800 \mathrm{~ms}$ duration was applied that included systole, increasing arterial pressure to over $300 \mathrm{~ms}$ from diastolic $(80 \mathrm{~mm} \mathrm{Hg})$ to peak systolic pressure $(120 \mathrm{~mm} \mathrm{Hg})$, followed by $500 \mathrm{~ms}$ of diastole, decreasing downward to minimum diastolic pressure.

\section{Data Analysis and Statistics}

Simulation results were examined at times corresponding to peak systolic pressures to measure wall stress and autograft diameter. The 99th percentile wall stress as previously described ${ }^{25}$ was examined in this study, because it more reproducibly represents peak stress by avoiding the nonphysiologic peak stresses that can occur from inhomogeneity in the FE mesh. References to peak wall stresses are represented by 99th percentile wall stresses. To measure maximum diameter, distances between the

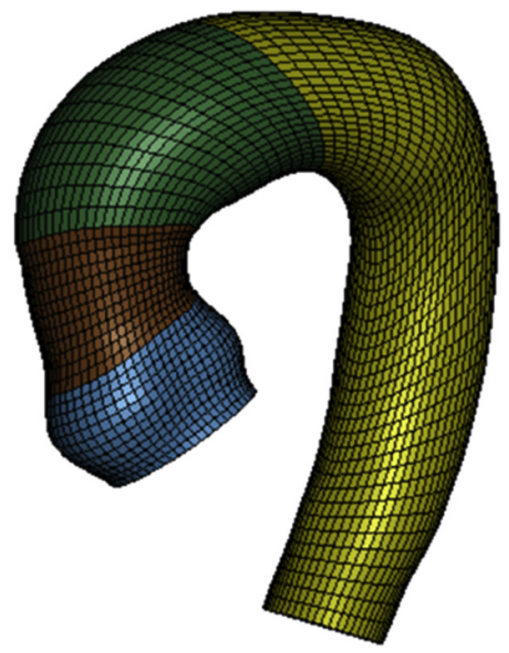

B

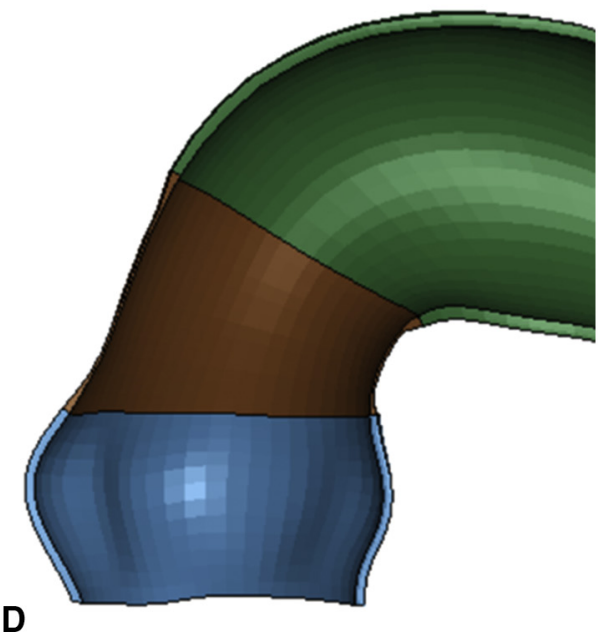

FIGURE 1. Representative 3-dimensional mesh models of pulmonary autograft and ascending aorta without (A) and with Dacron interposition graft (B); cross-section of autograft and ascending aorta mesh showing the thickness variation without (C) and with Dacron interposition (D). 
furthest sets of nodes on perpendicular planes to the centerline were tracked at each subregion of the root and ascending aorta. The reproducibility of the current study was performed by having authors E.A. and Y.X. independently develop separate sets of computational models from the MRI scans of each subject. Both performed independent FEA and stress distributions and magnitudes were compared. Validation of computational models was performed by comparing the model geometry with the MRI geometry.

Continuous measurements of autograft size and patient age are presented as mean \pm standard deviation, and wall stresses are presented as median and (25\%-75\%) interquartile range. Categorical measurements are presented as numbers and percentages. The data were tested for normal distribution using the Shapiro-Wilk test. Spearman rank correlation coefficients were used for the correlation between autograft diameter and wall stress, and continuous and categorical variables were compared using Mann-Whitney $U$ test and Kruskal-Wallis test, respectively. Statistical analyses were performed using R (R 3.6 www.r-project.org).

\section{RESULTS}

Table 1 identifies the clinical profiles of each Ross study patient. The study population was $63 \%$ male $(\mathrm{n}=10)$ and $37 \%$ female $(\mathrm{n}=6)$, with a mean age of $47.8 \pm 12.9$ years (range, $17-60$ years). Clinically, $81 \%(n=13)$ of the group had a bicuspid aortic valve and $19 \%(\mathrm{n}=3)$ had a unicuspid aortic valve, with $56 \%(\mathrm{n}=9)$ having aortic stenosis and the remainder having mixed stenosis and regurgitation. Average wall thicknesses of the pulmonary autografts and ascending aorta were $1.2 \pm 0.2 \mathrm{~mm}$ and $1.7 \pm 0.3 \mathrm{~mm}$, respectively. Postoperative mean pulmonary autograft size was $3.8 \pm 0.5 \mathrm{~cm}$, ranging from 3.1 to $4.8 \mathrm{~cm}$. Postoperative maximum autograft diameters were significantly larger in men than in women $(P<.001)$. Postoperative annulus diameters $(2.7 \pm 0.4 \mathrm{~cm})$ were significantly smaller than autograft STJ $(3.0 \pm 0.3 \mathrm{~cm}, P=.03)$, which were in turn smaller than sinuses $(3.8 \pm 0.5 \mathrm{~cm}, P<.001)$. Postoperative autograft sinus diameters were also significantly larger than those of the annulus $(P<.001)$ as expected.

In comparing the 1-year postoperative pulmonary autograft diameters with the preoperative aortic diameters at each subregion (14 of the 16 patients; Table 2), significant reduction of diameter was found at the annulus from $3.4 \pm 0.7 \mathrm{~cm}$ (preoperative aortic) to $2.7 \pm 0.4 \mathrm{~cm}$ (postoperative autograft $(P<.001)$ and $S T J$ from $3.3 \pm 0.7 \mathrm{~cm}$ (preoperative aortic) to $3.0 \pm 0.3 \mathrm{~cm}$ (postoperative autograft) $(P=.035)$. The diameter at the ascending aorta was not significantly different from preoperatively $(3.8 \pm 0.6 \mathrm{~cm})$ to postoperatively at 1 year $(3.6 \pm 0.4)(P=.15)$. No significant differences were found in the preoperative aortic sinus diameter $(3.8 \pm 0.7 \mathrm{~cm})$ and the postoperative autograft sinus diameter $(3.8 \pm 0.5 \mathrm{~cm})(P=.42)$ at 1 year.

The pulmonary autograft diameters did not change significantly at the annulus $(P=.29)$ from preoperative pulmonary pressures to postoperative aortic systemic pressures at 1 year $(2.8 \pm 0.7 \mathrm{~cm}$ vs $2.7 \pm 0.4 \mathrm{~cm}$, respectively, $P=.29)$. The autograft diameters at the STJ also did not significantly change from the preoperative pulmonary pressures to the postoperative aortic systemic pressures at 1 year $(2.9 \pm 0.5 \mathrm{~cm}$ vs $3.0 \pm 0.3 \mathrm{~cm}$, respectively, $P=.13)$. On the other hand, the sinus diameters of the pulmonary autograft did increase in size from the preoperative pulmonary position $(2.8 \pm 0.5 \mathrm{~cm})$ to the postoperative aortic position at 1 year $(3.8 \pm 0.5 \mathrm{~cm}), P<.001$.

At end systole, median first and second principal stresses on the pulmonary autograft overall, which approximately correlate with circumferential and longitudinal directions,

TABLE 1. Patient-specific characteristics $(N=16)$

\begin{tabular}{|c|c|c|c|c|c|c|c|c|}
\hline & Age & Sex & $\begin{array}{c}\text { Autograft } \\
\text { thickness }(\mathbf{m m})\end{array}$ & $\begin{array}{c}\text { Aortic } \\
\text { thickness }(\mathbf{m m})\end{array}$ & Dacron graft & NYHA & $\begin{array}{c}\text { Valve } \\
\text { morphology }\end{array}$ & $\begin{array}{c}\text { Stenosis/ } \\
\text { regurgitation/mixed }\end{array}$ \\
\hline 1 & 50 & M & 1.00 & 1.40 & $\mathrm{Y}$ & 3 & BAV & Mixed \\
\hline 2 & 58 & $\mathrm{~F}$ & 0.84 & 1.35 & $\mathrm{Y}$ & 2 & BAV & Stenosis \\
\hline 3 & 59 & $\mathrm{~F}$ & 1.36 & 2.05 & Y & 3 & BAV & Stenosis \\
\hline 4 & 57 & $\mathrm{~F}$ & 0.84 & 1.81 & Y & 2 & BAV & Stenosis \\
\hline 5 & 56 & M & 1.24 & 1.85 & $\mathrm{Y}$ & 3 & BAV & Mixed \\
\hline 6 & 50 & M & 1.29 & 2.29 & Y & 2 & BAV & Mixed \\
\hline 7 & 23 & $\mathrm{~F}$ & 0.69 & 1.24 & $\mathrm{Y}$ & 2 & BAV & Stenosis \\
\hline 8 & 60 & M & 1.29 & 1.81 & Y & 2 & BAV & Stenosis \\
\hline 9 & 28 & $\mathrm{~F}$ & 1.16 & $*$ & $\mathrm{~N}$ & 3 & UAV & Stenosis \\
\hline 10 & 53 & M & 1.15 & $*$ & $\mathrm{~N}$ & 3 & BAV & Mixed \\
\hline 11 & 52 & M & 1.32 & $*$ & Y & 3 & BAV & Stenosis \\
\hline 12 & 17 & $\mathrm{~F}$ & 1.19 & $*$ & $\mathrm{~N}$ & 2 & BAV & Mixed \\
\hline 13 & 53 & M & 1.4 & 1.78 & $\mathrm{Y}$ & 2 & BAV & Stenosis \\
\hline 14 & 54 & M & 1.48 & $*$ & $\mathrm{~N}$ & 1 & UAV & Mixed \\
\hline 15 & 41 & M & 1.35 & 1.625 & Y & 3 & UAV & Mixed \\
\hline 16 & 53 & M & 1.07 & $*$ & $\mathrm{~N}$ & 3 & BAV & Stenosis \\
\hline
\end{tabular}

NYHA, New York Heart Association; BAV, bicuspid aortic valve; $U A V$, unicuspid aortic valve. *Aortic thickness was not measured; averaged value used (1.84 mm). 
TABLE 2. Patient-specific pulmonary and aortic diameters

\begin{tabular}{|c|c|c|c|c|c|c|c|c|c|c|c|}
\hline & \multicolumn{3}{|c|}{$\begin{array}{c}\text { Pulmonary autograft preoperative: } \\
\text { maximum diameter }(\mathrm{cm})\end{array}$} & \multicolumn{4}{|c|}{$\begin{array}{c}\text { Aorta preoperative: } \\
\text { maximum diameter }(\mathrm{cm})\end{array}$} & \multicolumn{4}{|c|}{$\begin{array}{l}\text { 1-y Postoperative: } \\
\text { maximum diameter }(\mathrm{cm})\end{array}$} \\
\hline & Annulus & Sinus & STJ & $\overline{\text { Annulus }}$ & Sinus & STJ & $\overline{\mathbf{A A}}$ & $\overline{\text { Annulus }}$ & Sinus & STJ & $\overline{\mathbf{A A}}$ \\
\hline 1 & 2.4 & 2.7 & 2.5 & 3.4 & 3.7 & 3.0 & 3.5 & 2.9 & 3.8 & 3.2 & 3.7 \\
\hline 2 & 2.0 & 2.2 & 2.2 & 2.3 & 2.8 & 2.1 & 3.5 & 2.2 & 3.1 & 2.7 & 3.1 \\
\hline 3 & 2.3 & 2.4 & 2.8 & 3.2 & 2.9 & 3.0 & 3.6 & 2.3 & 3.3 & 2.8 & 4.0 \\
\hline 4 & 2.9 & 2.8 & 2.7 & 3.1 & 3.8 & 3.7 & 4.3 & 2.4 & 3.5 & 2.9 & 3.0 \\
\hline 5 & 2.8 & 3.0 & 2.8 & 4.6 & 4.6 & 3.7 & 4.2 & 3.0 & 3.8 & 2.9 & 3.7 \\
\hline 6 & 2.2 & 2.3 & 2.7 & 3.6 & 3.9 & 4.1 & 4.4 & 2.5 & 3.9 & 2.9 & 3.4 \\
\hline 7 & 2.3 & 2.3 & 2.6 & 3.1 & 3.8 & 3.5 & 4.1 & 2.8 & 3.4 & 2.9 & 3.3 \\
\hline 8 & * & * & $*$ & * & * & * & * & 2.2 & 3.9 & 2.8 & 3.5 \\
\hline 9 & 2.4 & 2.6 & 2.3 & 2.2 & 2.4 & 2.2 & 2.6 & 1.9 & 3.1 & 2.7 & 3.0 \\
\hline 10 & 2.2 & 2.4 & 2.5 & 2.9 & 3.6 & 3.0 & 2.7 & 2.8 & 3.5 & 3.0 & 3.6 \\
\hline 11 & 3.2 & 3.2 & 3.4 & 4.0 & 4.6 & 4.2 & 4.5 & 2.8 & 4.2 & 3.0 & 3.9 \\
\hline 12 & * & * & * & * & * & * & * & 2.3 & 3.5 & 3.0 & 3.1 \\
\hline 13 & 3.1 & 3.0 & 3.0 & 3.8 & 4.3 & 4.0 & 4.2 & 3.0 & 4.4 & 2.9 & 3.6 \\
\hline 14 & 4.5 & 3.6 & 3.6 & 4.3 & 4.7 & 3.6 & 3.6 & 3.3 & 4.8 & 3.8 & 4.2 \\
\hline 15 & 3.9 & 3.9 & 3.8 & 4.3 & 4.3 & 3.5 & 4.1 & 2.8 & 4.8 & 3.0 & 4.2 \\
\hline 16 & 3.0 & 3.3 & 3.4 & 3.3 & 4.1 & 3.0 & 3.2 & 3.3 & 4.3 & 3.3 & 3.7 \\
\hline Average \pm SD & $2.8 \pm 0.7$ & $2.8 \pm 0.5$ & $2.9 \pm 0.5$ & $3.4 \pm 0.7$ & $3.8 \pm 0.7$ & $3.3 \pm 0.7$ & $3.8 \pm 0.6$ & $2.7 \pm 0.4$ & $3.8 \pm 0.5$ & $3.0 \pm 0.3$ & $3.6 \pm 0.4$ \\
\hline
\end{tabular}

$S T J$, Sinotubular junction; $A A$, ascending aorta; $S D$, standard deviation. *No preoperative imaging available.

were $651.1 \mathrm{kPa}(599.0-796.8 \mathrm{kPa})$ and $345.2 \mathrm{kPa}(317.2-$ $396.4 \mathrm{kPa})(P<.001)$ (Figure 2). Peak stresses in the autograft subregions, STJ, sinuses of Valsalva, and annulus, were also examined. Peak first and second principal stresses at autograft STJ were $808.8 \mathrm{kPa}(691.2-1219.0 \mathrm{kPa})$ and $359.7 \mathrm{kPa}(310.1-426.3 \mathrm{kPa})$, respectively $(P<.001)$. At autograft sinuses, peak first and second principal stresses were $566.7 \mathrm{kPa}(484.8-675.2 \mathrm{kPa})$ and $355.5 \mathrm{kPa}(319.7-$ $394.1 \mathrm{kPa})$, respectively $(P<.001)$. At the annulus, peak first and second principal stresses were $636.8 \mathrm{kPa}$ (554.7$755.0 \mathrm{kPa})$ and $271.9 \mathrm{kPa}(252.4-318.7 \mathrm{kPa})$, respectively $(P<.001)$. Above the autograft or Dacron STJ reinforcement, peak first and second principal stresses on the ascending aorta were $381.5 \mathrm{kPa}(333.9-413.2 \mathrm{kPa})$ and $183.9 \mathrm{kPa}(146.9-221.8 \mathrm{kPa})$, respectively $(P<.001)$. Overall, peak wall stresses in the autograft as a whole and in each subregion were significantly different between first and second principal stresses as related to circumferential and longitudinal directions.

When comparing the autograft subregions (Figure 3), peak first and second principal stresses were not significantly different between the autograft STJ and the annulus ( $P=.08$ and $P=.07$, respectively). Peak first principal stresses in the autograft sinuses were also not significantly different than in the annulus $(P=.27)$, or STJ $(P=.05)$. In contrast, peak second principal stresses in the autograft sinuses were significantly greater than in the annulus $(P=.01)$, but were not significantly different than in the STJ $(P=.95$, Figure 3$)$. Peak first and second principal stresses of all autograft subregions were significantly greater than those of the distal ascending aorta $(P<.001)$.

Among the 16 patients, 11 had an ascending aortic repair with Dacron interposition and 5 did not. Peak first principal stresses were significantly greater in those with Dacron interposition grafts than those without at the STJ, 895 (809-1280) $\mathrm{kPa}$ versus 507 (363-599) $\mathrm{kPa}$, respectively $(P=.002)$, and at ascending aorta, $387(377-479) \mathrm{kPa}$ versus 274 (274-309) $\mathrm{kPa}$, respectively $(P=.02)$, but not in the sinuses, 592 (511-828) $\mathrm{kPa}$ versus 488 (475-588) $\mathrm{kPa}$, respectively $(P=.21)$, or at the annulus, 671 (597$808) \mathrm{kPa}$ versus $565 \quad(479-600) \mathrm{kPa}$, respectively $(P=.05)$. Likewise, peak second principal stresses were significantly greater in patients who had Dacron interposition grafts than in those without at the STJ, 403 (360-512) $\mathrm{kPa}$ versus $219(206-255) \mathrm{kPa}$, respectively $(P=.003)$, and at the ascending aorta, 201 (184-240) $\mathrm{kPa}$ versus 137 (116-141) kPa, respectively $(P=.002)$, but not at the sinuses, 365 (349-441) $\mathrm{kPa}$ versus 321 (315-334) $\mathrm{kPa}$, respectively $(P=.14)$, or at the annulus, $290(266-331) \mathrm{kPa}$ versus $241(212-264) \mathrm{kPa}$, respectively $(P=.14)$.

When examining the relationship between peak autograft stresses and diameter, pockets of peak wall stresses occurred most often in the STJ region rather than the sinuses, which had the largest diameter (Figure 3). Correlation between maximum diameter and peak stresses was 


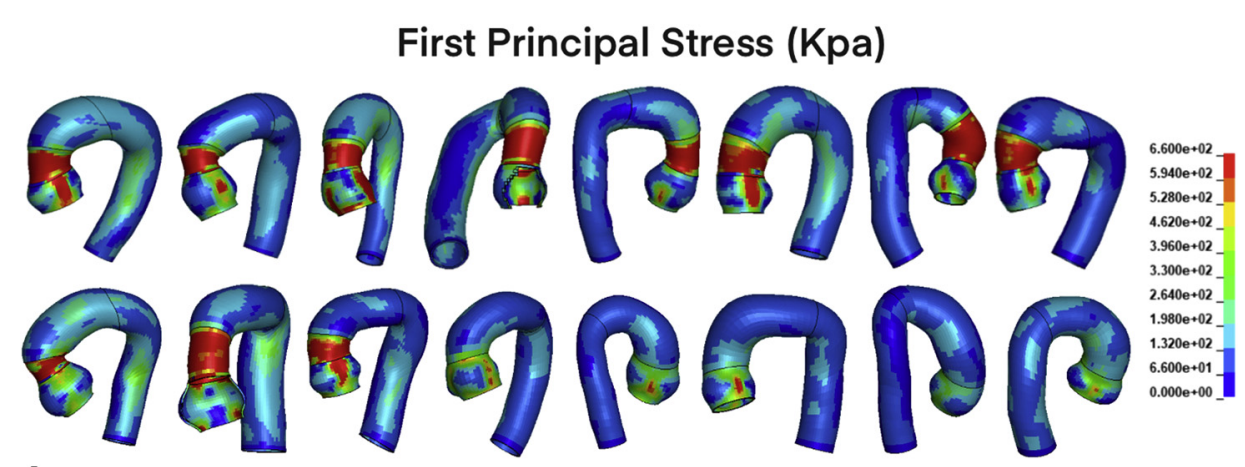

A

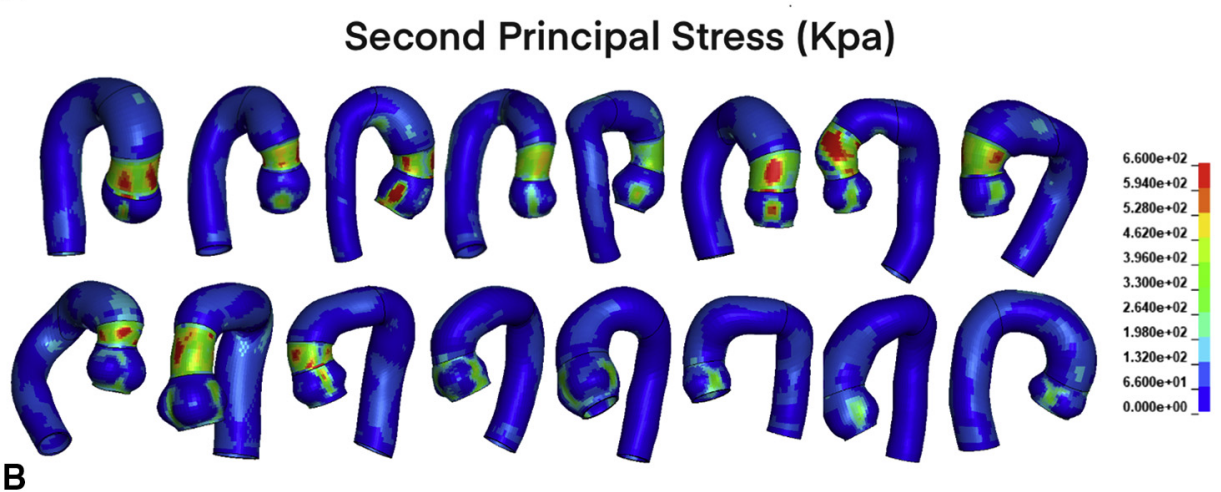

FIGURE 2. A, First principal wall stress profiles (circumferential stresses) of patient-specific autograft and ascending aorta models (top). B, Second principal wall stress profiles (longitudinal stresses) of patient-specific autograft and ascending aorta models (bottom). First row and the first 3 of the second row had Dacron interposition graft to the ascending aorta, and the remaining did not have a Dacron graft. Each individual patient in left-to-right order in (A) is reflected in the same order in (B).

extremely weak along both the circumferential $(\mathrm{r}=-0.29)$ and longitudinal $(\mathrm{r}=-0.21)$ directions (Figure E1). Autograft thickness was weakly related to the first principal stress $(\mathrm{r}=-0.48)$.

We examined the influence of patient-specific versus averaged material properties on wall stresses, because clinical determination of patient-specific material properties will be time-consuming and potentially challenging for clinical application. Overall, there were no significant differences in the magnitude and location of first and second principal stresses when using patient-specific versus averaged material properties. In each subregion, using patientspecific versus averaged material properties revealed no significant differences in first principal wall stresses in STJ $(P=.90)$, sinuses $(P=.98)$, annulus $(P=.98)$, and ascending aorta $(P=.72)$, and no significant differences in second principal wall stresses in STJ $(P=.70)$, sinuses $(P=.98)$, annulus $(P=.40)$, and ascending aorta $(P=.55)$. Detailed wall stresses in each subregion are shown in Table 3.

The distensibility from diastole to systole was calculated at each subregion of the pulmonary autograft (Table 4). Without Dacron replacement of the ascending aorta, distensibility of STJ was similar to the annulus. Distensibility of the sinus was generally less than at STJ and annulus.
Our computational models were validated by overlaying the geometry from MRI reconstructed images to geometry from our computational models at diastolic pressure (Figure E2). The geometry from our diastolic simulations tightly overlapped with those from MRI. Furthermore, in the reproducibility study, stress distribution of each aortic model between the 2 independent investigators was nearly identical, and variation of peak stress magnitudes was less than $6 \%$, which was within the accepted range of a prior interobserver study. ${ }^{26}$ Figure 4 summarizes the overall study design and results.

\section{DISCUSSION}

We studied the maximum diameters and patient-specific in vivo wall stresses of postoperative pulmonary autografts at 1 year after Ross operation. This study presents the most accurate patient-specific simulation by integrating imagebased geometry, experimental measurements of material properties from intraoperative tissue for each patient, and the detailed surgery technique with and without Dacron replacement of the dilated ascending aorta. Peak first and second principal stresses were seen at the autograft STJ and primarily driven by the placement of Dacron interposition graft. In all autograft subregions, peak first and second principal stresses were significantly greater than those in the 


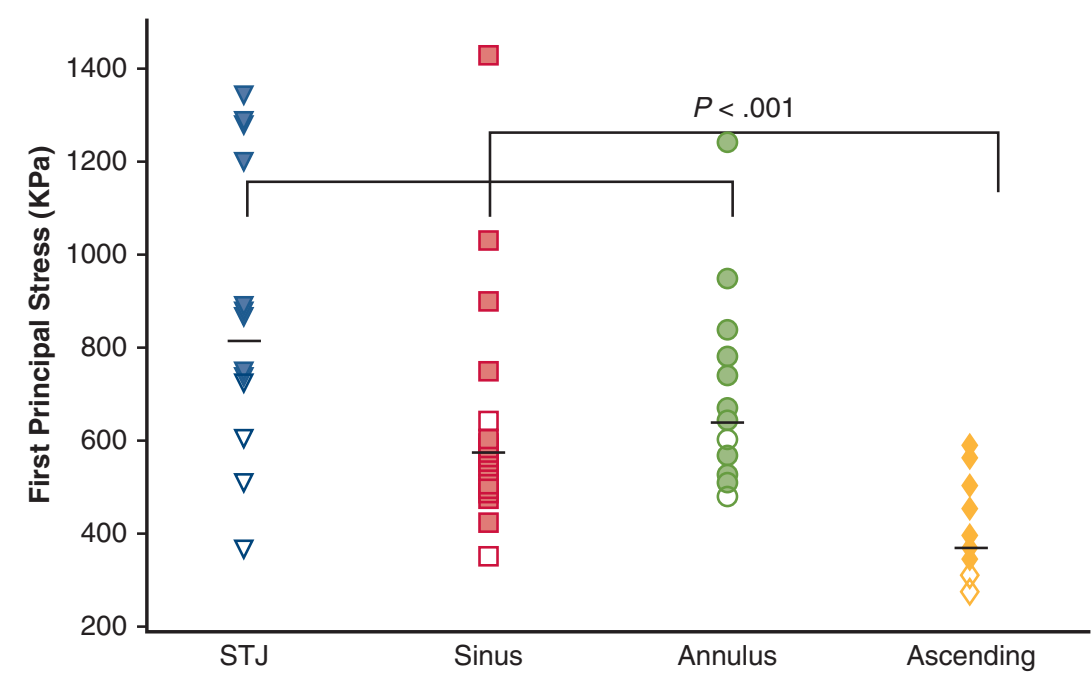

A

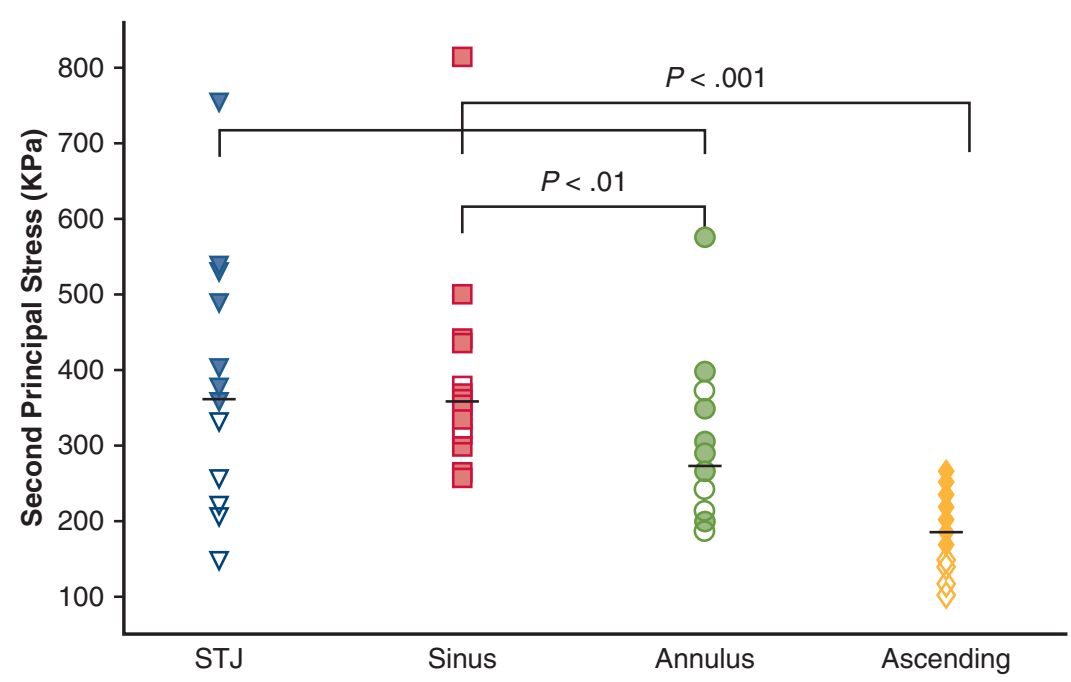

B

FIGURE 3. Comparison of autograft subregions and ascending aorta: peak first (A) and second (B) principal wall stresses (solid markers = patients with Dacron interposition; unfilled markers = patients without Dacron interposition; black bar = median value). The first and second principal stresses on STJ, sinus, and autograft annulus were higher than ascending aorta. The second principal stresses on sinuses were larger than in the annulus. STJ, Sinotubular junction.

distal ascending aorta. These elevated wall stresses along the autograft may trigger continued remodeling over time and may be associated with later autograft dilatation. At this early time-frame, autograft dilatation was not seen despite elevated autograft wall stresses compared with lower wall stresses in the corresponding native distal ascending aorta.

Understanding the magnitude and distribution of wall stress experienced by the pulmonary autograft as it moves from its low-pressure pulmonary circulation to systemic

TABLE 3. Peak first and second principal wall stresses in each subregion under systolic pressure, comparing patient-specific and group-averaged material properties 1 year after Ross procedure

\begin{tabular}{|c|c|c|c|c|c|c|}
\hline \multirow[b]{2}{*}{ (KPa) } & \multicolumn{3}{|c|}{ Peak first principal stress } & \multicolumn{3}{|c|}{ Peak second principal stress } \\
\hline & $\begin{array}{c}\text { Patient-specific } \\
\text { material property }\end{array}$ & $\begin{array}{c}\text { Average material } \\
\text { property }\end{array}$ & $P$ & $\begin{array}{c}\text { Patient-specific } \\
\text { material property }\end{array}$ & $\begin{array}{c}\text { Average } \\
\text { material property }\end{array}$ & $P$ \\
\hline STJ & $809(691-1219)$ & $777(689-1225)$ & .90 & $360(310-426)$ & $338(304-421)$ & .70 \\
\hline Sinus & $567(485-675)$ & $570(485-676)$ & .98 & $355(320-394)$ & $355(320-392)$ & .98 \\
\hline Annulus & $637(555-755)$ & $642(527-751)$ & .98 & $272(252-319)$ & $294(269-340)$ & .40 \\
\hline Ascending Aorta & $382(334-413)$ & $373(324-413)$ & .72 & $184(147-222)$ & $182(147-223)$ & .95 \\
\hline
\end{tabular}

Data presented as median (25\%-75\% interquartile range). STJ, Sinotubular junction. 
TABLE 4. Distensibility of the subregions of the pulmonary autograft

\begin{tabular}{lccc}
\hline \multicolumn{1}{c}{$\%$} & $\begin{array}{c}\text { With Dacron } \\
\text { replacement }\end{array}$ & $\begin{array}{c}\text { Without Dacron } \\
\text { replacement }\end{array}$ & $\boldsymbol{P}$ value \\
\hline STJ & $0.03 \pm 0.01$ & $3.38 \pm 0.69$ & .001 \\
Sinus & $0.99 \pm 0.28$ & $1.22 \pm 0.23$ & .087 \\
Annulus & $3.48 \pm 0.64$ & $4.20 \pm 0.44$ & .016 \\
\hline
\end{tabular}

Distensibility was defined as (perimeter at systole - perimeter at diastole)/perimeter at diastole. STJ, Sinotubular junction.

pressure fills a fundamental gap in knowledge to understand autograft remodeling. Autograft dilatation likely reflects the inability of the native pulmonary root to adapt to demands of the systemic circulation. Using computational modeling and FEA, we previously demonstrated in a single human autograft a significant 6-fold increase in autograft wall stress when exposed to the higher MAP $(\sim 93 \mathrm{~mm} \mathrm{Hg})$ in systemic circulation, from the lower MAP $(\sim 15 \mathrm{~mm} \mathrm{Hg})$ of pulmonary circulation. However, this model did not incorporate patient-specific material properties, unlike in our present study. ${ }^{21}$ In this study, by using patient-specific material properties and in vivo autograft geometries, autograft wall stresses 1 year after the Ross operation were still higher than their corresponding distal ascending aorta control regions, but no significant autograft dilatation was seen. This can be explained by the nonlinearity of the autograft stress-strain curve, where at systemic pressure the increased stiffness of the autograft material properties prevents early dilatation.

\section{Pulmonary Autograft Diameter}

Our results showed that in early autograft remodeling 1 year postoperatively, maximum diameter occurred as expected at the sinuses, whereas the STJ and annulus were well constrained. The average sinus diameter was $29 \%$ larger than in the STJ (38.3 $\mathrm{mm}$ vs $29.8 \mathrm{~mm})$, and $44 \%$ larger than in the annulus ( $38.3 \mathrm{~mm}$ vs $26.6 \mathrm{~mm}$ ). Compared with the preoperative baseline aortic annulus and STJ diameters, the postoperative autograft reduced the annulus and STJ diameters. However, the autograft preoperative diameters at pulmonary pressures did not significantly change from the autograft postoperative diameters at 1 year at the annulus and STJ. These findings suggest that the technique Dr El-Hamamsy used to place the autograft annulus in the subannular position constrained the annulus diameter postoperatively, just as the Dacron interposition graft at the STJ constrained the STJ from dilating at systemic pressure. However, the sinuses of the autograft did dilate from preoperatively at pulmonary pressures to postoperatively at 1 year at systemic pressures. The diameter of the autograft sinuses did not significantly differ in size postoperatively from the aortic sinuses preoperatively at systemic pressure. This suggests that at systemic pressure, the autograft achieved the size of the aortic sinuses, which is larger than the autograft sinuses at pulmonary pressures. It is reassuring that the autograft could achieve normal aortic sinus dimensions without dilatation. Clinical follow-up echocardiography of human pulmonary autografts after the Ross operation have shown sinus diameters of $36 \mathrm{~mm}$ immediately after cardiopulmonary bypass by Hokken and colleagues ${ }^{27}$ and $37.3 \mathrm{~mm}$ by Carr-White and colleagues. ${ }^{28}$ These results were well correlated to our sinus diameter of $38.3 \mathrm{~mm}$.

Clinically, STJ diameter was found to be an independent predictor of autograft regurgitation that led to reoperation. ${ }^{2}$ Failed autografts showed STJ dilatation without associated sinus dilatation, ${ }^{2}$ although this was not uniformly so and sinus dilatation was also demonstrated. Progressive autograft enlargement was found pronounced at the sinuses and STJ in 119 patients, whose mean sinus and STJ diameters increased from 30.8 to $42.4 \mathrm{~mm}$ and 26.6 to $32.2 \mathrm{~mm}$, respectively, at 10 years. $^{2}$ David and colleagues ${ }^{29}$ showed dilated sinuses with STJ dilatation with the aortic root replacement technique. Another group observed a trend of more marked STJ dilatation in serial follow-up over 4 years. ${ }^{28}$ Overall, these clinical follow-up studies suggest that STJ remodeling to accustom the autograft to systemic pressure may be critical in discerning autografts at risk of dilatation versus not. In this study, 11 patients had Dacron interposition that constrained STJ from dilatation postoperatively.

\section{Maximum Diameter and Peak Stress}

Peak stresses were not located in the region of maximum diameter in the majority of our study population, suggesting that factors such as complex noncylindrical geometries contributed to the stress distribution and were not well predicted by diameter using LaPlace's Law. Our results showed peak stresses in the STJ despite the largest diameter occurring in the sinuses. Because 11 of 16 patients had Dacron interposition, the Dacron graft had particular impact on wall stresses. Dacron interposition technically reinforces the STJ similarly to felt strip reinforcement. Notably our results showed that this reinforcement had no impact on stresses in the sinuses or annulus. STJ stresses were significantly greater as expected due to the transition from native autograft tissue to a thinner and stiffer Dacron material. One criticism of the Ross procedure is the need for reoperation due to autograft dilatation and aneurysm formation because of concern for autograft dissection or rupture. Because dissection/rupture can be considered a mechanical failure when wall stress exceeds wall strength, autograft dilatation alone may not be an indication for reoperation if the leaflets remain competent and autograft stresses do not exceed wall strength. Circumferential stresses account for autograft expansion, whereas longitudinal stresses control elongation. Although STJ circumferential stresses were largest, Dacron actively constrains the STJ diameter and prevents dissection propagation. The protective role of Dacron in this situation is similar to other Ross surgical techniques 
Wall Stresses of Early Remodeled Pulmonary Autografts
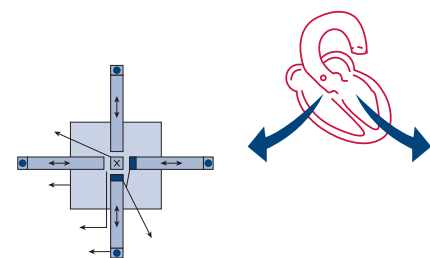

Methods: Biomechanical testing of aortic and pulmonary tissues and imaging follow up at 1-year post-operation after Ross procedure $(\mathrm{N}=16)$

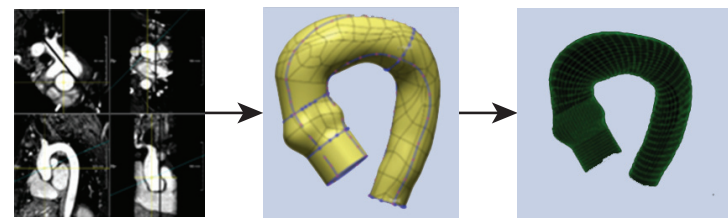

Results: 3D Patient-specific modeling based on medical imaging. Mean diameter of sinus: $38.4 \pm 5.3 \mathrm{~mm}$ at 1 year post-operation and mean diameter of sinotubular junction: $29.9 \pm 2.7 \mathrm{~mm}$.

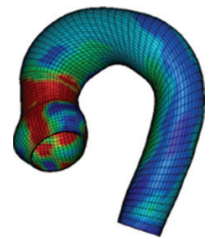

Results: Physiological stress via finite element analysis. Peak wall stress of pulmonary autograft: $651.1 \mathrm{kPa}$ vs. native distal ascending aorta: $382 \mathrm{kPa}$.

Implications: Further follow-up of wall stress patterns and dilatation may allow predictive model.

FIGURE 4. Of 290 patients undergoing the Ross procedure at the Montreal Heart Institute, a subset of 16 patients had autograft and aortic tissue removed during surgery for biaxial stretch testing for material properties and postoperative MRI at 1 year. Patient-specific modeling of pulmonary autografts were performed using 3-dimensional patient-specific imaging and material properties. FEAs were performed to determine wall stresses in the autograft and ascending aorta. The pulmonary autograft had significantly higher wall stresses than the distal ascending aorta (native internal control), which could drive remodeling over time. Future clinical follow-up can provide understanding of autograft biomechanics in relation to clinical dilatation.

to stabilize the STJ, such as STJ reinforcement with felt or full root inclusion as shown in previous studies. ${ }^{30-32}$ These techniques were found to promote longer freedom from reintervention.

The underlying biomechanical mechanism is similar in each of those scenarios. STJ stabilization with Dacron interposition, felt reinforcement, or full inclusion root techniques physically confines the STJ from later expansion to prevent remodeling. Dacron or felt provides strong support as a loading bearing structure that releases the high stress concentration and may drive the autograft remodeling given the strength of the materials. Because the sinuses are spared of the increased stresses with these techniques, other noninclusion root techniques may be protective of dilatation, such as partial inclusion of the noncoronary sinus aortic wall to support the autograft sinuses, as long as the STJ remains stabilized by Dacron or felt. In our models, both autograft STJ and sinuses had stresses that were greater than those of their respective distal ascending aorta, as well as those reported for normal human aortic sinuses (100$130 \mathrm{kPa}){ }^{33}$ Further follow-up over time of autograft stresses in these specific patients will be essential to understand if wall stresses diminish and approach normal aortic wall stresses over time. Understanding in vivo autograft sinus stresses will be important for correlation of future autograft dilatation.

This study is unique in that patient-specific material properties of pulmonary root and ascending aorta were available at the time of Ross operation to incorporate in the FE models along with in vivo MRI patient-specific 1-year postoperative Ross geometries to determine patient-specific wall stresses. As further understanding of Ross biomechanics is acquired during follow-up, the challenges in using biomechanics to predict adverse Ross remodeling and autograft dilatation will be to acquire patient-specific material properties in vivo. We have 
previously demonstrated the ability of displacement encoding with stimulated echocardiography MRI to determine patient-specific material properties in ascending thoracic aortic aneurysms ${ }^{34}$; however, our DENSE-MRI protocols at this time are vendor-specific, and our Siemen's based sequences were not available for the retrospectively acquired MRI scans from the Phillips scanners in Montreal. As such, we limited the study to those patients whose actual tissue specimens were available for material property assessment experimentally and examined the influence on FEA-derived stress results. We found no significant differences in wall stress magnitudes or distribution based on patient-specific versus averaged material properties (Table 3 ). With hundreds of patients who received a 1-year postoperative MRI but did not have intraoperative specimen collected, these results suggest we can reasonably approximate patient-specific wall stresses with group-averaged material properties. This will aid in simplifying the computational modeling process and applying FEA more broadly to the majority of Ross recipients with follow-up imaging.

We developed patient-specific Ross models to lay the foundation for understanding autograft remodeling over time. We hypothesize that higher autograft wall stresses drive autograft remodeling and that autograft dilatation results from abnormal remodeling responses such as increased autograft compliance as we previously found in failed autografts ${ }^{22}$ or failure of autograft wall stresses to normalize toward aortic wall stresses. This initial study of postoperative pulmonary autografts sets the stage to understand autograft wall stress changes over time in mid- and long-term follow-up with an expanded patient cohort. Patient-specific autograft simulations could fill the gap in knowledge of what leads to autograft dilatation. With the use of preoperative MRI, virtual Ross simulations of stress profiles coupled with evaluation of changes in stress distribution and magnitude over time at 5 to 10 years could identify predictors for dilatation. Anticipating which patients are at risk of autograft dilatation and thus during the Ross procedure require adjunctive preventative measures, such as Dacron inclusion root to support autograft sinuses, rather than proximal and distal support of noninclusion root with STJ stabilization with Dacron/felt or annular support, would be extremely beneficial given the additional technical complexities. For postoperative patients, early Ross remodeling simulations could stratify patients at higher risk for dilatation and aneurysm formation based on their postoperative imaging and allow opportunity for earlier medical optimization, such as stricter blood pressure control and more frequent follow-up.

\section{Study Limitations}

Although the application of the Ross procedure is not widespread, we selected the patients with intraoperative tissue and postoperative MRI scans, which further reduced the study cohort. Such a highly selected cohort ensured us to develop the most accurate computational models based on patient-specific geometry and material properties in this preliminary study. With this cohort of patients, we were able to have a proof of concept by identifying the extent wall stress plays in early remodeling and highlighting how averaged material properties may provide comparable results. This will allow us to further expand future studies to additional patients over longer follow-ups.

In our simulations, we focused on the effects of pressure loading on diameter and wall stress. As such, valve leaflets were not included in the models, because velocity distribution and flow characteristics using computational fluid dynamics or fluid shear stress using fluid-structure interaction were not examined.

Our goal was to create the best approximation of patientspecific models in the early postoperative period to establish a baseline for the remodeling process anticipated over the following 10 to 15 years. The material property was measured from an extracted intraoperative specimen; however, because of the clinical limitations, the earliest 3 -dimensional imaging available is 1 year postoperatively. Our previous study of failed Ross autografts indicated that the time of the autograft in circulation before autograft dilatation and reoperation was 13 years. ${ }^{22}$ We have no information regarding the time course of material property change, but it is reassuring that the autografts did not become aneurysmal at this time frame. These models were meant to reflect the postoperative baseline autograft stresses from which to compare future work with patient-specific follow-up at 5 and 10 years after the Ross procedure. This future follow-up will allow us to test the hypothesis that autograft biomechanical remodeling influences dilatation over time. Patient-specific material properties of aortic and pulmonary tissue are variable, as expected, based on variations in age, sex, and disease process, and as witnessed by surgeons in the operating room. Despite the variability in material parameters, we assessed the impact of averaged versus patient-specific material properties in the simulation results and found no significant differences. We plan to simplify future computational modeling processes for the majority of Ross recipients based on these data.

We used normotensive blood pressure of 120/80 mm Hg for all patients to assess wall stress consistently within the group, but clinically, these patients were subjected individually to strict blood pressure control, often $100 \mathrm{~mm} \mathrm{Hg}$ or less during the early remodeling period, to effectively reduce the peak autograft stresses.

\section{CONCLUSIONS}

Patient-specific modeling of the pulmonary autograft after the Ross procedure demonstrated greater in vivo wall stresses at the STJ, sinuses, and annulus when compared with the internal controls of wall stresses in the native distal 
ascending aorta at 1 year postoperatively. Despite elevated autograft wall stresses, no autograft dilatation was seen at this early time frame because of the stiffness of the autograft in that region of the stress-strain curve. Whether autograft wall stresses normalize to the magnitude of the native aorta over time will be important to determine in future studies. Dacron graft interposition anatomically constrained autograft dilatation at the STJ and is associated with increased STJ stresses due to the Dacron material stiffness, but had little effect in the annulus and sinus regions. This study fills a critical knowledge gap by examining patient-specific wall stresses in autograft subregions, as well as the influence of Dacron graft interposition at the STJ.

\section{Conflict of Interest Statement}

The authors reported no conflicts of interest.

The Journal policy requires editors and reviewers to disclose conflicts of interest and to decline handling or reviewing manuscripts for which they may have a conflict of interest. The editors and reviewers of this article have no conflicts of interest.

\section{References}

1. Laudito A, Brook MM, Suleman S, Bleiweis MS, Thompson LD, Hanley FL, et al. The Ross procedure in children and young adults: a word of caution. $J$ Thorac Cardiovasc Surg. 2001;122:147-53.

2. Kouchoukos NT, Masetti P, Nickerson NJ, Castner CF, Shannon WD, DavilaRoman VG. The Ross procedure: long-term clinical and echocardiographic follow-up. Ann Thorac Surg. 2004;78:773-81.

3. Mastrobuoni S, de Kerchove L, Solari S, Astarci P, Poncelet A, Noirhomme P, et al. The Ross procedure in young adults: over 20 years of experience in our institution. Eur J Cardiothorac Surg. 2015;49:507-13.

4. Sievers HH, Stierle U, Charitos EI, Takkenberg JJ, Horer J, Lange R, et al. A multicentre evaluation of the autograft procedure for young patients undergoing aortic valve replacement: update on the German Ross Registry. Eur J Cardiothorac Surg. 2016;49:212-8.

5. El-Hamamsy I, Eryigit Z, Stevens LM, Sarang Z, George R, Clark L, et al. Longterm outcomes after autograft versus homograft aortic root replacement in adults with aortic valve disease: a randomised controlled trial. Lancet. 2010;376: 524-31.

6. Pettersson GB, Subramanian S, Flynn M, Nowicki ER, Batizy LH, Svensson LG, et al. Reoperations after the ross procedure in adults: towards autograft-sparing/ Ross reversal. J Heart Valve Dis. 2011;20:425-32.

7. Stulak JM, Burkhart HM, Sundt TM III, Connolly HM, Suri RM, Schaff HV, et al. Spectrum and outcome of reoperations after the Ross procedure. Circulation. 2010;122:1153-8.

8. Schmidtke C, Bechtel J, Hueppe M, Noetzold A, Sievers HH. Size and distensibility of the aortic root and aortic valve function after different techniques of the Ross procedure. J Thorac Cardiovasc Surg. 2000;119:990-7.

9. Yacoub MH, El-Hamamsy I, Sievers HH, Carabello BA, Bonow RO, Stelzer P, et al. Under-use of the Ross operation-a lost opportunity. Lancet. 2014;384: 559-60.

10. Stelzer P, Itagaki S, Varghese R, Chikwe J. Operative mortality and morbidity after the Ross procedure: a 26- year learning curve. J Heart Valve Dis. 2013;22: 767-75.

11. Skillington PD, Mokhles MM, Takkenberg JJ, O'Keefe M, Grigg L, Wilson W, et al. Twenty-year analysis of autologous support of the pulmonary autograft in the Ross procedure. Ann Thorac Surg. 2013;96:823-9.

12. Charitos EI, Stierle U, Hanke T, Bechtel M, Sievers HH, Petersen M. Pulmonary homograft morphology after the Ross procedure: a computed tomography study. J Heart Valve Dis. 2011;20:688-94.

13. Luciani GB, Casali G, Favaro A, Prioli MA, Barozzi L, Santini F, et al. Fate of the aortic root late after Ross operation. Circulation. 2003;108:II61-7.
14. Mokhles MM, Rizopoulos D, Andrinopoulou ER, Bekkers JA, RoosHesselink JW, Lesaffre E, et al. Autograft and pulmonary allograft performance in the second post-operative decade after the Ross procedure: insights from the Rotterdam Prospective Cohort Study. Eur Heart J. 2012;33:2213-24.

15. Charitos EI, Stierle U, Hanke T, Schmidtke C, Sievers HH, Richardt D. Longterm results of 203 young and middle-aged patients with more than 10 years of follow-up after the original subcoronary Ross operation. Ann Thorac Surg. 2012;93:495-502.

16. Sievers H, Dahmen G, Graf B, Stierle U, Ziegler A, Schmidtke C. Midterm results of the Ross procedure preserving the patient's aortic root. Circulation. 2003;108(Suppl 1):II55-60.

17. Forcillo J, Cikirikcioglu M, Poirier N, El-Hamamsy I. The Ross procedure: total root technique. Multimed Man Cardiothorac Surg. 2014;2014:mmu018.

18. Stelzer P, Weinrauch $S$, Tranbaugh RF. Ten years of experience with the modified Ross procedure. J Thorac Cardiovasc Surg. 1998;115:1091-100.

19. Charitos EI, Hanke T, Stierle U, Robinson DR, Bogers AJ, Hemmer W, et al. Autograft reinforcement to preserve autograft function after the Ross procedure: a report from the German-Dutch Ross Registry. Circulation. 2009;120: S146-54.

20. Carrel T. The autograft inclusion: an obligatory step to avoid late failure following the Ross procedure? J Thorac Cardiovasc Surg. 2015;149:S53-4.

21. Wisneski AD, Matthews PB, Azadani AN, Mookhoek A, Chitsaz S, Guccione JM, et al. Human pulmonary autograft wall stress at systemic pressures prior to remodeling after the Ross procedure. J Heart Valve Dis. 2014;23:377-84.

22. Mookhoek A, Krishnan K, Chitsaz S, Kuang H, Ge L, Schoof PH, et al. Biomechanics of failed pulmonary autografts compared with normal pulmonary roots. Ann Thorac Surg. 2016;102:1996-2002.

23. Dionne PO, Wener E, Emmott A, Cartier R, Mongrain R, Leask R, et al. The Ross procedure: biomechanical properties of the pulmonary artery according to aortic valve phenotype. Interact Cardiovasc Thorac Surg. 2016;23:371-6.

24. Xuan Y, Wang Z, Liu R, Haraldsson H, Hope MD, Saloner DA, et al. Wall stress on ascending thoracic aortic aneurysms with bicuspid compared with tricuspid aortic valve. J Thorac Cardiovasc Surg. 2018;156:492-500.

25. Speelman L, Bosboom EM, Schurink GW, Hellenthal FA, Buth J, Breeuwer M, et al. Patient-specific AAA wall stress analysis: 99-percentile versus peak stress. Eur J Vasc Endovasc Surg. 2008;36:668-76.

26. Xuan Y, Dvir D, Wisneski A, Wang Z, Ye J, Guccione J, et al. Impact of transcatheter aortic valve size on leaflet stresses: implications for durability and optimal grey zone sizing. Asialntervention. 2020;6:64-71.

27. Hokken RB, Bogers AJ, Taams MA, Schiks-Berghourt MB, van Herwerden LA, Roelandt JR, et al. Does the pulmonary autograft in the aortic position in adults increase in diameter? An echocardiographic study. J Thorac Cardiovasc Surg. 1997;113:667-74.

28. Carr-White GS, Kilner PJ, Hon JK, Rutledge T, Edwards S, Burman ED, et al. Incidence, location, pathology, and significance of pulmonary homograft stenosis after the Ross operation. Circulation. 2001;104:I16-20.

29. David TE, Omran A, Ivanov J, Armstrong S, de Sa MP, Sonnenberg B, et al. Dilation of the pulmonary autograft after the Ross procedure. J Thorac Cardiovasc Surg. 2000;119:210-20.

30. Brown JW, Ruzmetov M, Shahriari AP, Rodefeld MD, Mahomed Y, Turrentine MW. Modification of the Ross aortic valve replacement to prevent late autograft dilatation. Eur J Cardiothorac Surg. 2010;37:1002-7.

31. Slater M, Shen I, Welke K, Komanapalli C, Ungerleider R. Modification to the Ross procedure to prevent autograft dilatation. Semin Thorac Cardiovasc Pediatr Card Surg Ann. 2005;8:181-4.

32. Jacobsen RM, Earing MG, Hill GD, Barnes M, Mitchell ME, Woods RK, et al. The externally supported Ross operation: early outcomes and intermediate follow-up. Ann Thorac Surg. 2015;100:631-8.

33. Grande KJ, Cochran RP, Reinhall PG, Kunzelman KS. Stress variations in the human aortic root and valve: the role of anatomic asymmetry. Ann Biomed Eng. 1998;26:534-45.

34. Krishnan K, Ge L, Haraldsson H, Hope MD, Saloner DA, Guccione JM, et al. Ascending thoracic aortic aneurysm wall stress analysis using patient-specific finite element modeling of in vivo magnetic resonance imaging. Interact Cardiovasc Thorac Surg. 2015;21:471-80.

Key Words: computational modeling, dilatation, finite element analysis, pulmonary autograft, remodeling, Ross procedure, wall stress 

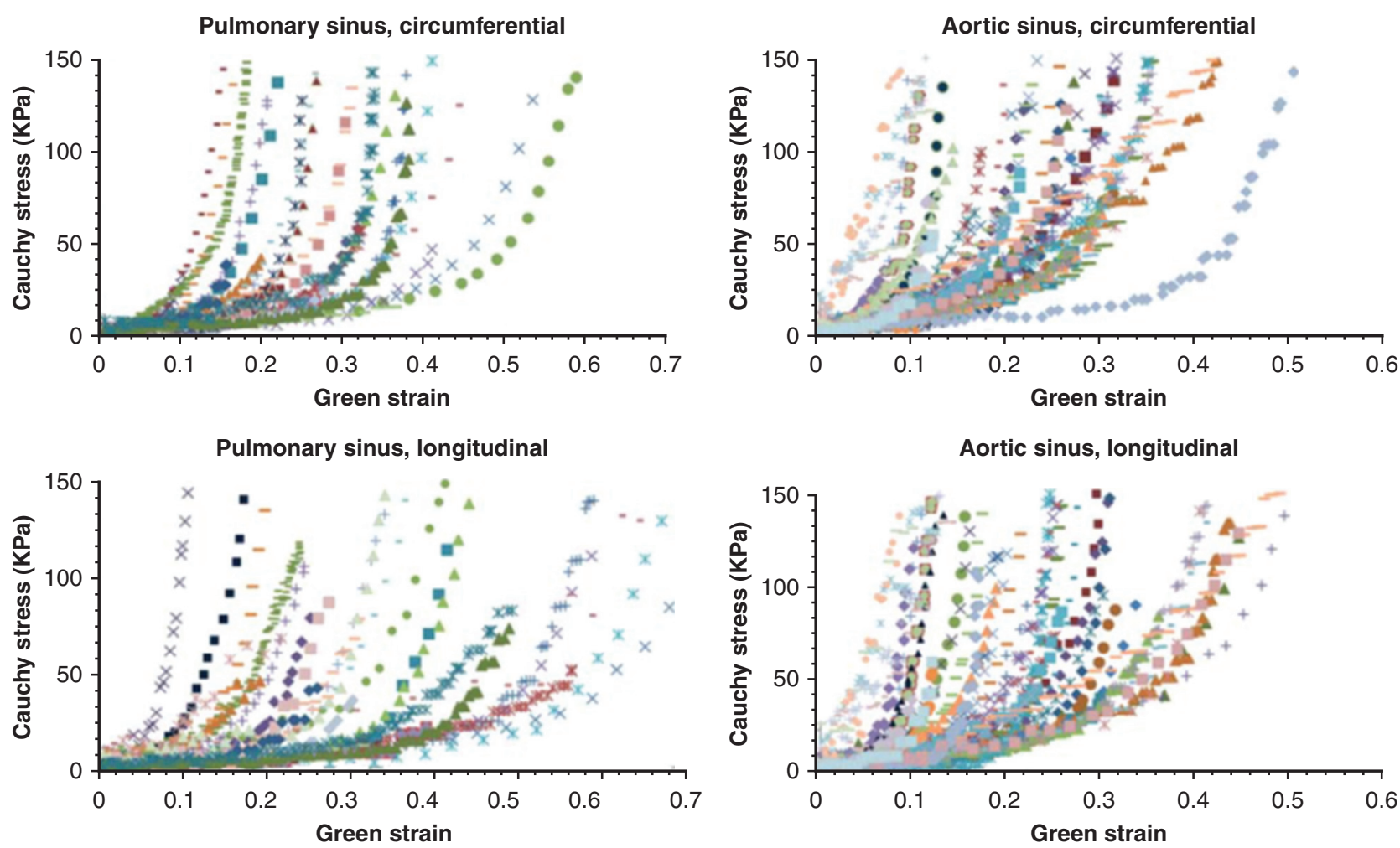

FIGURE E1. Weak correlation between autograft peak first principal stresses and autograft diameter (upper $)(P=.28)$ and weak correlation between autograft first principal stresses and autograft thickness (lower $)(P=.43)$.

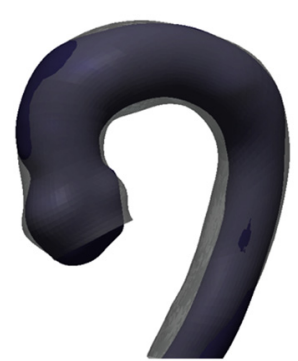

Diastolic

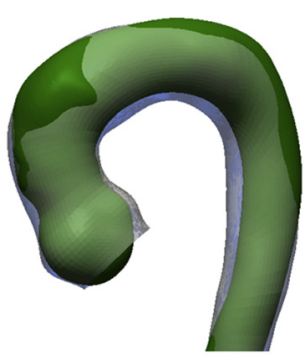

Systolic

FIGURE E2. Superimposition of a representative MRI-derived geometry (dark purple) and computational geometry (light grey) under diastolic (left) and systolic (right) pressures, which showed how well the geometries matched. 
TABLE E1. Patient-specific material parameters and averaged material parameters

\begin{tabular}{|c|c|c|c|c|c|c|}
\hline \multirow{2}{*}{$\frac{\text { Patient-specific }}{\text { Patient no. }}$} & \multicolumn{3}{|c|}{ Pulmonary } & \multicolumn{3}{|c|}{ Ascending aorta } \\
\hline & $k 1$ & $k 2$ & Fiber angle (rad) & $k 1$ & $k 2$ & Fiber angle (rad) \\
\hline 1 & 0.13 & 4.17 & 0.35 & 10.84 & 2.01 & 0.7 \\
\hline 2 & 0.1 & 3.73 & 0.42 & 16.04 & 3.28 & 0.48 \\
\hline 3 & 20.92 & 1.91 & 0.65 & 45.94 & 2.33 & 0.77 \\
\hline 4 & 14.59 & 1.36 & 0.78 & 44.09 & 0.78 & 0.8 \\
\hline 5 & 10.73 & 1.05 & 0.83 & 45.12 & 0.84 & 0.80 \\
\hline 6 & 11.06 & 4.14 & 0.79 & 49.48 & 1.59 & 0.87 \\
\hline 7 & 1.33 & 2.38 & 0.67 & 44.38 & 0.55 & 0.77 \\
\hline 8 & 6.61 & 1.92 & 0.82 & 86.53 & 0.01 & 0.54 \\
\hline 9 & 20.00 & 0.01 & 0.66 & $*$ & $*$ & 0.71 \\
\hline 10 & 16.31 & 0.42 & 0.81 & $*$ & $*$ & 0.71 \\
\hline 11 & 17.57 & 0.37 & 0.68 & $*$ & $*$ & 0.71 \\
\hline 12 & 14.81 & 0.01 & 0.71 & $*$ & * & 0.71 \\
\hline 13 & 8.23 & 1.85 & 0.63 & 45.92 & 0.35 & 0.72 \\
\hline 14 & 11.70 & 0.99 & 0.76 & $*$ & $*$ & 0.71 \\
\hline 15 & 15.58 & 1.15 & 0.75 & 53.90 & 0.48 & 0.71 \\
\hline 16 & 25.48 & 0.17 & 0.69 & * & $*$ & 0.71 \\
\hline Averaged Material Parameters & 12.20 & 1.60 & 0.69 & 44.22 & 1.22 & 0.71 \\
\hline
\end{tabular}

*The cohort-averaged material property of the ascending aorta was used when patient-specific aortic tissue specimen was not extracted. 